\title{
Model of Learning Management Applying the Five Precepts for Thai Students
}

\author{
Phrasuwanmahaphuthaphibal (Ho Subhaddo) ${ }^{1}$, Phrakrusoponpattaravet (Ittipol Padhãniko) ${ }^{2}$, \\ Phrakrukosolpariyattayanukij (Tharueti Virojano) ${ }^{3}$, Somsak Boonpoo ${ }^{4}$. \\ ${ }^{1,2,3,4}$ Faculty of Education, Mahachulalongkornrajavidyalaya University \\ 1'howattrimitr@gmail.com, ${ }^{2}$ oodwatsaymai@gmail.com, ${ }^{3}$ konkuandee@gmail.com, ${ }^{4}$ somsak2499@ hotmail.com
}

\begin{abstract}
The purposes of this research were 1) to study the state of learning management in the context of Thai schools, and 2) to develop and propose a model of learning management applying the five precepts for Thai Students. Mixed methods research was used for the design. Qualitative data were collected by in-depth interview from 17 key informants, and to confirm results using focus group discussion. Quantitative data were collected by using questionnaires from 390 samples. Content analysis was used for the qualitative data whereas quantitative data was analyzed by descriptive statistics consisted of percentage statistics, frequency, mean, standard deviation. Results indicated that the state of learning management in the context of Thai schools consisted of 1) Learning Management in 4 areas: (1) Basic preparation, (2) Planning and preparation of learning management, (3) using psychology of learning, (4) evaluation and reports. 2) Five Precepts of learning management of the 5 Precepts for Thai students consisting of the 1st Precepts is no slaughtering of animals; the 2nd Precepts is no theft; the 3rd Precepts is prohibited behavior; the 4th Precepts is prohibiting to be posted; the 5th Precepts is prohibition drink alcohol. 3) Schools need to organize learning management applying 5 precepts. There should be participation among administrators, teachers, school board members, monks, parents, students and communities. Therefore, LFS Model was developed composed of 3 important points which were (1) Learning Management, (2) Five Precepts, and (3) School.
\end{abstract}

Keywords

Learning Management, Five Precepts, Thai Students

Article Received: 10 August 2020, Revised: 25 October 2020, Accepted: 18 November 2020

\section{Introduction}

Thailand has been practicing Buddhism for a long time by being the main institution and the identity of the Thai people. It has been a way to bind the minds of Thai people for a long time which the doctrine of Buddhism, and aims to encourage logical thinking and being together in peace (Faculty of Mahachulalongkornrajavidyalaya University, 2009: 27) [1]. Therefore, the importance of the development of physical, mental and social behavior is very important for human life. The physical and mental health of any person is in perfect health, and being able to control body and mind very well, the mind is responsible for controlling and directing every function of the body to work efficiently [2] of coexistence in society happily. Religion has five precepts, called Benjasin, as a basic guideline for virtue in order to be able to refine and refine human traits to be more refined and to behave, and deeds of goodness, restraint, and mindfulness to act, to speak, to think, must first ponder carefully [3]. Violating the rights of others with some physical or some way of property humans will feel terrified, and insecure in life and property. If the society is controlled by the precepts and does not violate each other by the body or the word, our society will be quite [4], being calm, comfortable, not burning with lust, anger and rulers, is a person with honest body, honesty and conscience, so the 5th precept is a practice that is beneficial to society and for the peace of the society as well [5].

The application of the principles of Buddhism to apply in daily life according to the nature of the problem according to the intellect and will of the individual. Therefore, there are various levels of teaching of Buddhism, both basic, middle and high. It is called the world of morality and the world. Morality is the basic teaching or at the basic level all teachings is a practice system because teachings are truth is caused by real experience. The teachings will have real results only to those who practice them. The precepts are the same although it is a very basic teaching, but if people implement them correctly, they will have relationships with other systems, and developed to the highest level as the Lord Buddha said "The precepts look like this, concentration looks like this, intelligence looks like this, individual concentration training under the precepts will have a lot of results and great merit, intelligence which a person is trained by concentration as a base is of great influence. A person's mind is trained with wisdom as the base will naturally be liberated by the likes of the trash, namely Gamasawa, Bhavasawa, and Avichasawa."

The introduction of the principles of Buddhism to be used in daily life according to the nature of the problem according to the intellect and will of the individual. Therefore, there are various levels of teaching of Buddhism, both basic, medium, and advanced. There are both parts called it is the philosophy and the world applying principles to solving problems of society is important in Thai society. At present, in every society there is a leader who are knowledgeable and able to lead members towards the goals that have been laid out together Thai society is the same. There will always be a leader with Buddhist leadership, meaning someone who is well-rounded, visionary, knowledgeable, capable, responsible for the work, and have personal relationship skills look at the subordinates positively, fair to have a heart, and know love unity. There is a sacrifice without persistence, without prejudice, which 
virtue. These must exist in the leadership of the leader to maximize the benefits and efficiency of their work through self-management, people management and organizational management. In the way of Buddhism, it is considered to be a leader who has good Buddhist leadership, and must have qualifications according to Buddhist principles. A leader who has a Buddhist leadership to lead another person in the footsteps of Buddhism, it is considered a very important person. The larger the organization the importance of a leader with Buddhist leadership to its members is becoming more and more important. Any organization who has a good Buddhist leadership will be good as well. On the other hand, any organization has a leader without Buddhist leadership, the organization has to face difficulties in the management of that organization.

In the management system of every organization, the key mechanism that will lead to a good goal is "leader". Management includes planning initiatives, management, supervising and implementing solutions to solve problems to achieve the goals of the organization. Leaders are influencers that can affect every aspect of the organization, be it management and personnel. Leadership is the process by which executives influence the behavior of others. One of the most important success factors in leadership roles is being a good leader is right, so every organization needs to have a good leader. School administration is to be effective according to the aims of the National Education Act. Executives must use leadership to distribute the responsibility fairly to the subordinates in their respective units. In this globalized era, management needs to be able to adapt leadership to various changes and solve problems that arise to be suitable for every situation, and use their knowledge and capabilities to benefit the effective management. Good management should have the ability to manage the work by allowing the personnel to cooperate with the willingness and the full capability. Executives must have the ability to build morale and encouragement to the operators to achieve job satisfaction, the love and faith in the organization, sacrifice for work, exert energy and encouragement mind power, looking for ways to improve the work that progresses even further.

The school is an institutional center of society, second to the family, formed by social needs to perform the main duty of organizing teaching and learning activities for members of society by providing education and teaching, and to develop people to flourish in knowledge, competence, morality, morality, good culture, honesty, sacrifice and willingness to train together, work in various missions for the benefit of society. Education is a learning process in what is an important process that people develop their abilities in both attitude and behavior according to social values including the process of transferring knowledge in both ordinary and vocational lines, morals and important cultures, as a guideline for behavior and use of knowledge to benefit society which is a good attitude of kindness and treats the public in a good way. It gives rise to skills, fluency, and dexterity to follow in the proper manner of moral boundaries both outside behavior and virtue within up to the present and future trends to be used as a model and way of living in the past. Teaching and learning is not consistent with the living environment, and not keeping up with the changes of society progress in science and technology because teaching focuses on theory and knowledge. As a result, students lack the processes of thinking, analysis, problem solving and adapting to the changing conditions of the environment. These things arise from the policy of educational administration, some of which are not suitable for the context of each educational institution. Therefore, there are additional changes to suit the Thai education as much as possible [6].

For that reason, the researcher is therefore interested in the study of the 5 precepts learning management model for primary school students under Bangkok focusing on the application of the five precepts, teaching methods, the application of the 5 precepts to manage learning in schools as a guideline for the development of school curriculum, create motivation of stakeholders, interest in innovation ideas, and control work for the development of teaching and learning of all subjects especially leading to an efficient Buddhist school.

\section{Research Objectives}

The purposes of this research were 1) to study the state of learning management in the context of Thai schools, and 2) to develop and propose a model of learning management applying the five precepts for Thai Students.

\section{Research Method}

For this study, researchers used a survey research model, along with in-depth interview and focus group discussion, which was a mixed methods research between quantitative research and qualitative research by analyzing data from documents, textbooks, statistical data, research reports of various departments, academic articles, thesis as well as relevant research work, and a formal in-depth interview by using the interview questionnaire created by the researcher to study the opinions of school administrators who were target groups as a case study. Questionnaires were distributed to teachers in schools under the Primary Education Service Area Office, totaling 390 copies. An interview was conducted by interviewing 20 key informants consisting of school administrators, and questionnaires for focus group discussion with 11 experts. The researcher collected the data and analyzed the data as follows: 1) qualitative data was analyzed by using content analysis, 2) quantitative data were analyzed by using descriptive statistics consisted of percentage, frequency, mean, standard deviation. 3) Data from interview was analyzed using content analysis and summarizing results according to interview form, and 4) data from focus group discussion was also analyzed by using content analysis.

\section{Research Findings}

The results of the study of the 5 precepts of Thai students were as follows:

The level of opinions on the learning management of the 5 precepts of the four areas of primary school students consisted of 1) basic preparation, 2) planning and preparation of learning management, 3) using learning psychology, 4) assessment. The results and reports found 
that the overall opinions on the 5 precepts learning management of Thai students was at a high level, in each side, at high level in all aspects.

The results of the study of the 5 precepts learning management model for Thai students. The 5 precepts learning management model should be shared among administrators, teachers, school directors, monks, parents, students and communities. The 5 precepts learning management should be more involved in 4 areas: 1) preparation with basics, 2) planning and preparing for learning management, 3) using learning psychology, 4) evaluation and reporting. In addition, all stakeholders should be involved in the development of the school by using the guidelines for presenting the 5 precepts learning management model for Thai students

The results of the presentation of the 5 precepts learning management model for Thai students. Five precepts learning management model for Thai students from schools in Bangkok has 3 important focus that should be added in learning management. The 5 precepts should be shared among administrators, teachers, school directors, monks, parents, students and communities. There are four areas: 1) basic preparation, 2) planning and preparation of learning management, 3) application of learning psychology, 4) evaluation and reporting. 3. Should be accessible to all stakeholders. Let's take part in school development by using the guidelines for presenting the 5 precepts learning management model for Thai students of schools in Bangkok. The results of the study of the 5 precepts of Thai students. The level of opinions on the learning management of the 5 precepts of primary school students in all four areas were 1) basic preparation, 2) planning and preparation of learning management, 3) using learning psychology, and 4) assessment. The results and reports found that the overall opinions on the 5 precepts learning management of Thai students was at a high level, in each aspect was also at a high level in all aspects.

The results of the study of the 5 precepts learning management model for Thai students. The 5 precepts learning management model should be shared among administrators, teachers, school directors, monks, parents, students and communities. The 5 precepts learning management should be more involved in 4 areas: 1) basic preparation, 2) planning and preparing for learning management, 3) using learning psychology, 4) evaluation and reporting. In addition, all stakeholders should be involved in the development of the school by using the Guidelines for presenting the 5 precepts learning management model for Thai students of schools in Bangkok The results of the presentation of the 5 precepts learning management model for Thai students. The 5 precepts learning management model for Thai students of schools in Bangkok 3 important focus should be added with learning management. The 5 precepts should be shared among administrators, teachers, school directors, monks, parents, students and communities. There are four areas: 1) basic preparation, 2) planning and preparation of learning management, 3) application of learning psychology, 4) evaluation and reporting. There should be accessible to all stakeholders who take part in school development using the 5 precepts learning management model guidelines for Thai students of school in Bangkok.

\section{Discussions}

The opinions towards the learning management of the 5 precepts of Thai students in all four areas consisted of 1) basic preparation, 2) planning and preparation of learning management, 3) using learning psychology, and 4) evaluation and the report found that the overall opinion on the 5 precepts learning management of Thai students same level. This is because there is a very effective learning of the 5 precepts which is related to the research of Kanchana Chanprasert (2011) [7], on "Development of a self-guided learning model by using problems as a base for teaching physics and biological sciences". A problem-based selfguided learning model in the teaching of physics, biological sciences, developed with four elements as follows (1) The principle of the model, (2) the purpose of the model, (3) the teaching and learning process. It consists of 8 steps: learners preparation, problem solving, problem analysis, planning, research, synthesis, summary, evaluation of learning, and (4) evaluation of performance. The image of the model was shown by t-test of post-study scores of the experimental group and the control group, showed statistically significant differences at the .05 level and was consistent with the research results of Dhevarit Phonyaim (2016) [8] who have researched on "The model of learning management according to the philosophy of sufficiency economy in primary education institutions. Under the supervision of the Office of the Roi Et Primary Educational Service Area 3 ", the research found that the situation and current condition of the learning management according to the philosophy of sufficiency economy in the primary school level under the Office of Roi Et Primary Educational Service Area 3, the overall level was at a high level. When considering each aspect, it also showed at a high level in all 7 aspects, ranked in descending order of average score, namely organizational organization, reporting, planning directories, Personnel management, coordination and budgeting, respectively. The model of learning management according to the philosophy of sufficiency economy in primary schools under the Office of Roi Et Primary Educational Service Area 3, it was found that the elements of the learning management model based on the philosophy of sufficiency economy in primary education institutions under the Office of Roi Et Primary Educational Service Area 3, it consists of 7 elements as follows: 1) organizing learning activities according to the needs of learners and localities, 2) having appropriate lines of command, 3) personnel development, 4) director of learning management activities, 5) building cooperation in community and non-corporate organizations, 6) supervision, monitoring and review of performance, and 7) budget management planning. For the evaluation of the model of learning management model based on the philosophy of sufficiency economy in primary schools, the Office of Roi Et Primary Educational Service Area 3 was found to be correct, suitability and feasibility agree on a high level.

The management of the fifth precepts should be shared among the administrators, teachers, school directors, monks, parents, students and the community. 2) Planning and preparing for learning management, 3) Using learning psychology, 4) Evaluation and reporting. In addition, all stakeholders should be involved in the development of the school by using the guidelines for presenting the 5 precepts 
learning management model for primary school students. For schools under Bangkok which is consistent with the research of Phatcharee Srisang [9] has conducted research on "Development of a learning management model for social psychology using community and experience as a base to enhance the desirable characteristics of the graduates." The results showed that (1) the development of this learning management model was developed in the form of Co-generative Action Research based on the concept of David and Morten. (Greenwood, J. Davydd \& Leven Morten) 2 phases in three consecutive cycles: 1) First phase: giving meaning or clarifying the initial question (cycles of research), 2) continuous phase: research, action to solve problems that have gathered various dimensions (2nd and 3rd round), a structural conceptual framework guiding principles of learning management in a systematic way of 8 elements are: 1) problems and needs for learning management, 2) principles of learning management, learning management model, 3) Purpose of the learning management model, 4) Expected outcome, 5) Subject, 6) Learning activity, 7) Evaluation of the model, and 8) learning resources. (2) Desirable characteristics of the graduate students after using the model of learning management, the knowledge of consciousness had an average score in the emotional level, and the average score was in the high level. All skills have a high average score except for observing skills at the highest level, higher as compared to before using the learning management model. The average score was in the improvement level. The emotional state was at a moderate level and all skills were at a negligible level, except for observational skills at a moderate level. The difference was statistically significant at the .05 level, based on the effectiveness criteria of the learning management model, and (3) effective Ya dong community members. Participated in learning activities for the first and second round, the members of the dance club exercise, dance, first, exercise, who took part in organizing learning activities through the third round of knowledge, everyone is able to learn consciousness, emotions, feelings, and all skills except for group work skills that all members praised Ya Dong in the first round did not learn about the second round, most of the Ya Dong community members took up lessons to know and also consistent with the research of [10] has been researched on "Development of a management model to learn about history to strengthen basic thinking skills of students in grades 4-6, "The research found Studying problems and solutions for developing basic thinking skills, it was found that $57.07 \%$ of Grade $4-6$ students had basic thinking skills at the level below $50 \%$.

The results of problem analysis and guidelines for developing basic thinking skills of students in grades 4-6 from inquiries and interviews with teachers Student interview. The relevant teachers group discussion found that the educational activities strengthen the basic thinking skills at each level still faced the greatest level of learning management problems while the solutions and recommendations of teachers were learning management provides learners with appropriate patterns to develop such thinking skills. The creation of a learning management model. It synthesizes related theoretical concepts, which are: 1) linking learning theory, 2) discovery learning theory, 3) constructivist theory, 4) problem solved learning theory, 5 ) knowledge tracing learning concept, 6) cooperative learning theory concept, 7) Brain-based learning concept. The results of the synthesis of learning management models consist of concepts, theories, principles, objectives, learning processes, knowledge, principles and systems for promoting learning and conditions for implementing the learning management model. The learning management process was designed to consist of 5 phases: 1) preparation phase, 2) problem coping phase and rational analysis, 3) discussion and conclusion, 4) generalization phase of knowledge, and 5) exchange of knowledge and evaluation while the results from the seminar based on a group of experts to confirm the pattern and receive comments and suggestions, it was found that the format was appropriate to a large extent. When the model was put into trial, it was found that the model-based learning management was effective classified by grade 4-6 were $79.81 / 78.75,77.41 / 76.88$ and $78.56 / 77.94$, respectively. The effectiveness index (EI) was 0.56, 0.59, and 0.61, respectively, and the results of the implementation of the learning management model to enhance basic thinking skills of Grade 4-6 students found that (1) figure the learning management model for building basic thinking skills developed and applied at each level was 83.09 / 82.75,79.80 / 79.38 and 84.37 / 81.43, respectively, and the effective index (E1 / E2) was found. EI were 0.63, 0.64, and 0.66 respectively, and have more basic thinking skills after study than before. There was statistical significance at .01 level and (3) Grade 4-6 students in the experimental group that were managed learning according to the model ability to have basic thinking skills after class. They were significantly higher than the control group studied by normal method at .01 level at all levels.

The 5 precepts learning management model for Thai students of schools in Bangkok has 3 important focus should be added. The 5 precepts should be shared among administrators, teachers, school directors, monks, parents, students and communities. There are four areas: 1) basic preparation, 2) planning and preparation of learning management, 3) application of learning psychology, 4) evaluation and reporting, 3 . There should be accessible to all stakeholders who take part in school development using the 5 precepts learning management model guidelines for Thai students of schools under the Bangkok Metropolitan Administration, which is consistent with the research results of Al-halal (2001),[11] the impact of activities was studied on individual teaching and cooperative learning that affect academic achievement, mathematics and social skills use of primary school students tested the effects of two methods of teaching mathematics teaching in primary school, namely individual teaching, cooperative on achievement. The study of mathematics and the use of social skills among primary school students. The research results showed that teaching and learning management using a cooperative learning method resulted in the learning mathematics of higher students, the organization of teaching and learning activities individually. Therefore, teaching and learning using a cooperative learning method can help increase achievement level in mathematics and the use of social skills of students in grade 2. From the statistical analysis results, it was found that all interviewees have consensus. They also prefer the collaborative learning method, and it is consistent with the research of Ziegler, Michele Flasch (2001) [12] studied that 
the impact of community-based instructional management on ordinary students and special needs together in a secondary school. The results of this study, it was found that the school structure Teacher's beliefs practice and their experiences and experiences have influenced the management of community-based teaching and learning. Learners will gain skills, specific and have greater understanding learners develop three key skills: (1) communication skills, (2) leadership and citizenship, and (3) working with people. It is effective that the learners gain knowledge and understanding in 4 areas: (1) learn that there are various methods of learning, (2) learn how to work in real working situations, (3) begin to find out what the community is. Community is a living resource and it is a learning center of the school, and (4) has shed their knowledge and understanding of the school curriculum that has been studied better. There are three limitations for the condition: (1) the natural proportion of the normal learners with the less capable learners, (2) the preferences of the learners. It is determined by peer groups as input, and (3) teachers and mentors must be aware and understand the nature of the class. Community-based teaching and learning management must be able to connect classroom learning or have the purpose of combining the academic skills and learning opportunities of the learner. Finally, the limitation or continuity of the study arrangement. There are five aspects of community-based teaching: (1) lack of classes, (2) the number of classes with specific needs is overloaded, (3) the reach of people, all lessons learned will be learned in this method, (4) the limitations of learners who have little ability to learn this way, and (5) community-based teaching and learning, and the base does not provide the learner with repeated practice continuously.

\section{Recommendations}

\section{Recommendation for general suggestions}

Research results on the 5 precepts learning management model for Thai students. The results of the study, the researcher had the following recommendations.

1. Schools should promote vegetarianism or healthy vegetarian that must be patient, and know how to restrain the first precepts.

2. Schools should coordinate with families who must take care of them, and promote the quality of life since childhood.

3. Schools should cultivate awareness of the problems that will follow and campaigning for polite Thai dress.

4. The school should be rigorous with language culture matters, organize activities to attend the temple, and must be instilled to be honest and ashamed, which must be instilled from a young age.

5. Schools should campaign to educate people on the dangers of drinking alcohol, closed liquor factory and punishing heavily, controlling society, making merit without alcohol and should not drink alcohol while driving more serious in the law.

\section{Recommendation for further research}

If there is further research on the management of the 5 precepts, the researcher recommends conducting research in the following ways:
1. There should be a management development study according to the five precepts for the quality of good school administration. Each of the key components should be carefully studied in order to be accepted that the components that will really affect the quality of education in the school.

2. There is further research on the development of indicators for administrative excellence according to the 5 precepts of the school.

3. The research results obtained should be applied to schools or the next unit considering the achievement in learning management of the 5 precepts of the school.

\section{Conclusion}

The learning management of the five precepts of Thai students in all four areas consisted of 1) basic preparation, 2) planning and preparation of learning management, 3) using learning psychology, and 4) assessment and report. The overall level was at the high level while each aspect was at the high level in all aspects. The development of the 5 precepts learning management model for Thai students. The 5 precepts should be shared among administrators, teachers, school directors, monks, parents, students and communities. The management of the fifth precepts should be more involved in 4 areas: 1) the preparation of blessings, 2) planning and preparing for learning management, 3) using learning psychology, 4) evaluation and reporting. In addition, all stakeholders should be involved in the development of the school by using the guidelines for presenting the 5 precepts learning management model for primary school students. For the 5 precepts learning management model for Thai students in schools under Bangkok Metropolitan Administration (LFS Model), there will be 3 important focus points: 1. Learning Management, learning management in 4 areas: 1) basic preparation, 2) learning management planning and preparation, 3) learning management using learning psychology, 4) Evaluation and report. 2. Five Precepts Learning management 5 precepts for Thai students. For schools affiliated in Bangkok, there are 1) the first precepts must not kill animals, 2) the second precepts do not steal, 3) the third precepts must not behave in the erotic, 4) the fourth precepts do not lie, 5) the fifth precepts do not drink alcohol. 3. School, the school must conduct a learning arrangement. The 5 precepts should be shared among administrators, teachers, school directors, monks, parents, students and community.

\section{References}

[1] Mahchulalongkornrajavidyalaya University, Thai version of the Tipitaka Chulalongkornrajavidyalaya, Bangkok: Mahachulalongkornrajavidyalaya Printing House, 1996.

[2] R. Sangsuk and others, Knowledge of virtue Bangkok: Pimluk, 2007.

[3] B. Taenkaew, Buddhism. Bangkok: Printed at O.A. Printing House, 2005. 
[4] W. Inthara. Puttajariya, Bangkok: Ordinary publishing house, 2007.

[5] Phra Thewin Tewinto, Virtue Sciences, Bangkok: Rung Saeng Publication, 2007.

[6] P. Siha-ampai, Fundamentals of Religious and Ethical Education, Bangkok: Chulalongkorn University Press, 2010.

[7] K. Chanprasert, "Developing a selfguided learning model using problems as a base for Teach physical science, biological science ", Doctor of Philosophy of Education. Graduate School, Rangsit University, 2011.

[8] T. Phonyaim, A model of learning management based on the philosophy of sufficiency economy in primary schools under the Office of the Roi Et Primary Educational Service Area 3, Journal of Graduate Studies Suan Sunandha Rajabhat University. Vol 2, No 2 (2016), 275-292.

[9] P. Srisang. "Development of a model for learning management in social psychology using community and experience as a base for enhancing the desirable characteristics of the graduates," Doctor of Education Dissertation Research and curriculum development programs, Graduate school Srinakharinwirot University, 2008.

[10] Y. Piewon, "Development of management style, learning about history to strengthen the skills basic thinking of students in grades 4-6 ", Doctor of Philosophy Desis in Curriculum Innovation and Learning, Graduate School: Mahasarakham University, 2015.

[11] A. J . Al-Halal, "The effect of individualistic learning and cooperative learning strategies on elementary students' mathematics achievement and use of social skills," Dissertation Abstracts International, 62 (5): 1697-A; November, 2001.

[12] M.F., Ziegler, (2001). The Impact of Inclusive Community-Based Instruction on Students Identified as "Gifted". "Typical" and "Special Needs Learners" in a High School: An Exploratory Study, Retrieved November 20, 2018, from http // wwwlib.umi.com / dissertations /fullcit / 3012575 